Revista de Estudios Histórico-Jurídicos

[Sección historia del derecho patrio chileno]

XXXIX (Valparaíso, Chile, 2017)

[pp. 351 - 376]

\title{
STATU QUO DE LA SIMUlaCión DEL MATRIMONIO. ANTES Y DESPUÉS DE LA NuEVA LEY DE MATRIMONIO CIVIL
}

[Statu quo of the simulation of the marriage. Before and after of the New Civil Marriage Act]

\author{
Alexis Mondaca Miranda* \\ Universidad Católica del Norte, Antofagasta, Chile**
}

\begin{abstract}
RESUMEN
En el presente artículo se estudia la falta de una regulación explícita de la simulación a propósitodel matrimonio civil. Luego de una breve referencia al estado de la cuestión en el derecho canónico, se analiza la disciplina otorgada a la materia por el CC y por la LMC de 1884 . A continuación, se estudian las discusiones relativas a la simulación surgidas durante la tramitación del proyecto de ley que se convertiría en la Ley No 19.947, para finalmente referirnos a la ausencia de tratamiento expreso de la simulación en la NLMC, lo que no impide
\end{abstract}

\begin{abstract}
In this article we will study the absence of an explicit regulation of the simulation on the subject of civil marriage. After a brief reference to the state of the matter in Canon Law, we analyze the discipline given to the subject by the CC and by the LMC of 1884 . We will then study the discussions regarding the simulation that emerged during the course of the project of Law that would become Law No. 19,947, to finally refer to the absence of an express treatment of the simulation in the NLMC, the above
\end{abstract}

ReCiBIDO el 7 de abril y ACEPTADO el 23 de junio de 2017

* Profesor de derecho civil de la Escuela de Derecho de la Facultad de Ciencias Jurídicas de la Universidad Católica del Norte, Antofagasta, Doctor en Derecho por la Pontificia Universidad Católica de Valparaíso y Máster en Empresa, Derecho y Justicia por la Universidad de Valencia. Dirección postal: Avenida Angamos 0610, Antofagasta, Chile. Correo electrónico: amondaca@ucn.cl.

** Este artículo se inscribe en el proyecto Fondecyt de Iniciación 2015 No 11150118 , "La incidencia de los vínculos de familia en la resolución de las acciones de amparo deducidas para revocar las decisiones administrativas de expulsión de extranjeros”. El autor agradece al Programa Fondecyt el financiamiento de la presente investigación. 
que dicho supuesto sea sancionado con la inexistencia.

Palabras Clave
Matrimonio - Simulación -
Consentimiento. does not preclude its punishment with the non-existence.

KEYwORDS
Marriage - Simulation - Consent.

\section{INTRODUCCIÓN ${ }^{* * *}$}

En este trabajo se estudia la simulación del matrimonio ${ }^{1}$. Esta figura ha recibido un tratamiento disímil a lo largo de los años. Veremos que desde un primer estadio en el que se le reconocía relevancia jurídica, se ha llegado a una etapa en la que ni siquiera es mencionada por la normativa especializada matrimonial. Analizar dicha evolución y las causas que la motivaron, es el objeto de la investigación que emprendemos.

Para lo anterior, distinguiremos dos períodos. El primero de ellos se refiere a Chile, capitanía general del imperio español, y concluye con la LMC de 1884. El segundo inicia con la mencionada regulación y representa el estado actual de la materia, comprendiendo, en consecuencia, la disciplina realizada por la NLMC.

En el primer período se aplicaba el derecho canónico; luego, la simulación era un impedimento para contraer matrimonio reconocido por el derecho de la Iglesia católica. Por consiguiente, forzoso resulta referirnos, brevemente, a la disciplina de la simulación realizada por el derecho canónico. Panorama distinto puede apreciarse en la segunda etapa, dado que la simulación no es objeto de tratamiento expreso. Así, no se encuentra en el elenco de causales de nulidad matrimonial de la LMC. Tampoco el legislador de 2004 se refirió en términos explícitos a la simulación, no figurando ésta en las causales de nulidad de matrimonio.

La realidad ha demostrado que no es baladí la situación de la simulación en el sistema matrimonial. Para fundamentar la última afirmación, tengamos en cuenta dos supuestos de simulaciones matrimoniales que se producen en la actualidad. En primer lugar, la inmigración ha planteado una serie de desafíos al ordenamiento jurídico en su conjunto y al derecho de familia, en particular. En este sentido, los relevantes, y cada vez más crecientes flujos de inmigrantes que recibe Chile², han

Tabla de abreviaturas: IC. Ius Canonicum; LMC. Ley de matrimonio civil de 1884; NLMC. Nueva ley de matrimonio civil; RCD. Revista Chilena de Derecho; RDF. Revista de Derecho de Familia; RDP. Revista de Derecho Privado; REDC. Revista Española de Derecho Canónico; RDUCV. Revista de Derecho de la Universidad Católica de Valparaiso.

${ }^{1}$ Salinas Araneda, Carlos, El influjo del derecho canónico en el Código Civil de la República de Chile (Valparaíso, Ediciones Universitarias de Valparaíso, 2006), pp. 93-104.

${ }^{2}$ Sobre la base de los datos proporcionados por los censos del Instituto Nacional de Estadísticas, el crecimiento de la población extranjera ha sido el siguiente: 83.805 (Censo 1982); 105.070 (Censo 1992); 184.464 (Censo 2002); y 441.529 (estimación 2014). A similar conclusión conducen las cifras del Departamento de Extranjería y Migración del Ministerio del 
dado nuevos bríos a las voces que se preguntan sobre el status de la simulación en el derecho de familia. En concreto, apuntamos a un fenómeno al que nos hemos referido en otras oportunidades: los usualmente llamados matrimonios de conveniencia o matrimonios de complacencia ${ }^{3}$, entre otras denominaciones, aunque según nuestro parecer más correcta es la expresión matrimonios internacionales migratorios simulados. ${ }^{4}$

Los matrimonios de conveniencia son aquellos celebrados entre un extranjero y un nacional del país receptor respectivo. Entre otras características, en ellos no existen un auténtico consentimiento matrimonial, lo verdaderamente perseguido es la obtención de un beneficio en sede de extranjería, como la residencia, la nacionalización, evitar la expulsión del territorio nacional, etc. ${ }^{5}$ En consecuencia, no se buscar instaurar una comunidad de vida conyugal respetuosa de los fines del matrimonio que prescribe el artículo 102 del Código Civil. Como ya indicamos, el matrimonio es tratado como un simple medio para el logro de determinados beneficios.

En segundo término, se acude al matrimonio con el exclusivo fin de obtener beneficios de índole previsional. Nos referimos a matrimonios celebrados entre un miembro de las Fuerzas Armadas y otra persona que no pertenece a dichas instituciones. Sabido es que el régimen común previsional de Chile es objeto de fuertes críticas. Al mismo tiempo, el sistema previsional de las Fuerzas Armadas concede mayores beneficios a sus afiliados. En este contexto, en la última etapa de su vida, un militar contrae matrimonio (normalmente con una amiga o pariente no incluido en el impedimento dirimente relativo de parentesco), de forma tal

Interior y Seguridad Pública, organismo que para el año 2014 estimó que la población extranjera residente en Chile ascendía a 415.540

3 Mondaca MiRANDA, Alexis, De los matrimonios simulados, comúnmente denominados matrimonios de conveniencia o matrimonios por complacencia, de su prueba y de la lucha jurídica en su contra, en Domínguez hidalgo, Carmen et al. (coords.), Estudios de derecho civil VIII. Jornadas nacionales de derecho civil, Santa Cruz (Santiago de Chile, LegalPublishing Thomson Reuters, 2012), pp. 105-114.

${ }^{4}$ También se les llama matrimonios $\mathrm{fr}$ a u d u le $\mathrm{n} \mathrm{to} \mathrm{s}$, matrimonios b la n c o s o matrimonios g r i s e s (esta es la terminología que se aprecia en Francia), matrimonios c o n v e n i d o s y matrimonios $1 \mathrm{u}$ to. La denominación matrimonios i n t e r n a c i o $\mathrm{n}$ a les sim ulados migratorios tiene mayor precisión técnica. Al decir que son i $\mathrm{n}$ e $\mathrm{r} n$ a c i o $\mathrm{n}$ a $\mathrm{l}$ e $\mathrm{s}$ se indica que las partes poseen diversas nacionalidades. La voz s i m u la d o s manifiesta que no se trata de matrimonios propiamente tales, sino que de la apariencia de los mismos. Con el término $\mathrm{m}$ i g r a $\mathrm{t}$ o $\mathrm{r}$ i o $\mathrm{s}$ se identifica su objetivo: son una simulación especial, vinculada con ciertas ventajas en materia de derecho de extranjería. Véase, también, MONDACA MIRANDA, Alexis, Reflexiones sobre uno de los desafios que la inmigración plantea al derecho de familia: los asi denominados matrimonios de conveniencia, en ELORRIAGA DE BONIS, Fabián (coord.), Estudios de derecho civil IX. Jornadas nacionales de derecho civil, Viña del Mar, 2011 (Santiago de Chile, Abeledo Perrot LegalPublishing, 2011), pp. 41-54.

5 Los extranjeros amenazados por la ejecución de una orden de expulsión de la autoridad administrativa intentan dejarla sin efecto, en sede judicial, mediante la acción de amparo. Uno de los fundamentos de dichas acciones son los vínculos de familia constituidos por el inmigrante, MONDACA MIRANDA, Alexis, Los nexos de familia y la revocación de las resoluciones de expulsión de extranjeros, en Lepín Molina, Cristián (coord.) Estudios de derecho familiar (Santiago de Chile, Thomson Reuters, 2016), I, pp. 373-388. 
que su cónyuge, una vez producido el fallecimiento, pueda ser titular de ciertos beneficios previsionales, como pensiones de viudedad. Como podemos apreciar, al igual que en los "matrimonios de conveniencia", no existe ánimo de comenzar una verdadera convivencia marital y no se persigue ninguno de los fines propios del matrimonio, sino que se busca exclusivamente un beneficio patrimonial.

En breves palabras, en ambos casos se trata de supuestos de simulación, porque la voluntad que han declarado los contrayentes no coincide con su voluntad real o interna. Por lo tanto, como una exigencia derivada de la lógica y de la justicia, el ordenamiento jurídico debe reaccionar en contra de las simulaciones matrimoniales; éstas producen la inexistencia del matrimonio, en atención a la ausencia de un requisito de existencia, como lo es el acuerdo de voluntades de los cónyuges. No obsta a lo señalado, la falta de una disciplina expresa de la simulación, como veremos con mayor detalle en su momento. De lo expresado, se deriva la relevancia del tratamiento que el derecho matrimonial otorgue a la simulación, y la importancia que poseen estas líneas.

\section{LA APLICACIÓN DEL DERECHO CANÓNICO. LA SIMULACIÓN COMO CAUSAL DE NULIDAD}

En este epígrafe veremos cómo la simulación fue reconocida en Chile como una causal de nulidad, dado que en una época se aplicaba el derecho canónico, en consecuencia, como se indicó en la introducción, una referencia al tratamiento de la simulación en dicho ordenamiento resulta fundamental para nuestro análisis. En lo que nos hemos permitido denominar primera etapa de la disciplina chilena de la simulación, subdistinguiremos dos períodos. El primero abarca el espacio de tiempo previo a la dictación del Código Civil, mientras que el segundo, desde el 1 de enero de 1857, fecha de inicio de vigencia del mencionado código, hasta antes de la LMC de 1884.

\section{Estado de la materia antes de la entrada en vigencia del Código Civil}

En el derecho canónico la simulación tiene una gran relevancia. En este sentido, "consensus facit nuptias", o como se precisaba en el derecho del medioevo, "simulatae nuptiae non sunt nuptiae". Siguiendo a Donoso, el consentimiento es esencial para el valor del matrimonio y, en términos más amplios, de todo contrato $^{7}$. No obstante lo anterior, el término simulación no ha sido utilizado por el Codex Iuris Canonici de 1917 ni por el Código de Derecho Canónico de 1983, al contrario de lo que sucede con la doctrina y con la jurisprudencia, quienes con frecuencia emplean la voz simulación ${ }^{8}$. Con todo, reputadas voces efectuaron matices de entidad ${ }^{9}$. De esta manera, algunos autores se oponían a

\footnotetext{
${ }^{6}$ Panormitanus, in $\mathrm{X} 4,1,26$.

7 Donoso, Justo, Instituciones de cerecho canónico (París, Librería de Rosa y Bouret, 1854), II, p. 364.

${ }^{8}$ Moreno Ramírez, Domingo, Relevancia de la sacramentalidad del matrimonio en relación con la nulidad del consentimiento (Madrid, Ediciones Universidad San Dámaso, 2014), p. 247.

9 Para un mayor desarrollo de la materia, véase, GAS AIXENDRI, Monserrat, La formulación
} 
su eficacia invalidante, salvo que su origen se encontrase en la coacción o en el dolo. Así lo entendía Pedro Lombardo ${ }^{10}$. Agréguese a lo anterior la opinión de Sicardo de Cremona, quien sostuvo que debía primar la voluntad declarada por sobre la voluntad interna ${ }^{11}$.

Por simulación se entiende en sede canónica, siguiendo a Aznar, "la discrepancia intentada deliberadamente por el simulante entre la voluntad interna y su manifestación o declaración externa, equivaliendo generalmente a ficción, es decir, a un acto que hace surgir en otros un falso juicio. Jurídicamente es la discrepancia o divergencia entre el acto externo, que alguien pone al realizar un acto jurídico, y la verdadera voluntad interior, que rechaza ese acto y desvirtúa lo realizado. Es decir: consiste en realizar un acto que tiene un preciso contenido y valor según la determinación de la ley con una intención completamente diversa". ${ }^{12}$

No debe confundirse la simulación con el error ni con la ignorancia. En el error existe una falsa representación de la realidad, como lo ha planteado Bañares, un conocimiento errado, en cambio, a propósito de la ignorancia el conocimiento de la realidad es insuficiente ${ }^{13}$. Nada de ello ocurre en la simulación, en la que ambos contrayentes, de común acuerdo, por un acto positivo de voluntad han decidido no desear contraer matrimonio, no obstante que exteriormente dan a entender una voluntad favorable al mismo.

Desde antiguo, en sede canónica, la simulación ha sido considerada una causal de nulidad del matrimonio. Hervada, comentando los decretales de Graciano, explica que "en resumidas cuentas, en este texto, fundamental en materia de simulación; se tipifica este «caput nullitatis» por una voluntad positiva de producir el signo externo del negocio matrimonial con un fin práctico distinto al conyugal, junto a una carencia de una voluntad matrimonial de contenido; en otras palabras, por una manifestación de voluntad, sin consentimiento interno" ${ }^{\text {. }}$. Lo mismo

del concepto "acto positivo de voluntad", contrario al matrimonio hasta el CIC 1983, en KowAL, J. y Llobell, J. (eds.), "Iustitia et iudicium”. Studi di Diritto matrimoniale e processuale canonico in onore di A. Stankiewicz, (Città del Vaticano, Libreria Editrice Vaticana, 2010), pp. 753-779.

${ }^{10}$ Lombardo, Pedro, Sententiarum libri quatuor (Antuerpiae, 1757), IV, dist. 27, N. 3.

11 Sicardo de Cremona, Summa, in. C. 29, q. 1.

${ }^{12}$ AzNar GIL, Federico, El nuevo derecho matrimonial canónico (2a edición, Salamanca, Bibliotheca Salmanticensis Estudios 60, Universidad Pontificia de Salamanca, 1985), II, p. 182.

13 BAÑARES, Juan Ignacio, Simulación y error-ignorancia, en BAÑARES, Juan Ignacio (dir.), Simulación matrimonial en el derecho canónico (Pamplona, Eunsa, 1994), pp. 146-147.

${ }^{14}$ HervadA, Javier, La simulación total (comentario a la sentencia de la S.R.R. de 22-11-1961 c. Canals), en Hervada, Javier, Vetera et Nova. Cuestiones de derecho canónico y afines (1958-1991), I, p. 250. Agrega el autor que: "La simulación total está, pues, suficientemente tipificada por una voluntad de realizar seriamente una manifestaci6n del consentimiento, junto a una ausencia de la voluntad interna de contraer el vínculo matrimonial. Hay, en la simulación, una discordancia querida entre la manifestación y la voluntad interna, una falsedad. Si quisiésemos resumir en breves rasgos en qué consiste la simulación total, lo haríamos con palabras de la sentencia rotal de I3-XII-I9I2 c. Prior: (Fictus seu simulatus consensus habetur quandocontrahens externe quidem verba consensum exprimentia serio et rite profert, interne autem non consentit. Cum contractus matrimonialis de essentia sua sit voluntarius, et actu ipsius voluntatis externe expresso perficiatur, defectus consensus interni ex lege naturae illum nullum reddit)". Ibíd., p. 293. 
acontecía en el Derecho romano: "simulatae nuptiae nullius momento sunt"15.

Decía el ilustre canonista Tomás Sánchez, razonando sobre la posibilidad de que Dios pudiese otorgar poder sobre el cuerpo de otro sin su consentimiento, que el matrimonio no implicaba el derecho de usar el cuerpo del otro, tampoco la obligación mutua, sino que el vínculo que unía a los contrayentes, y la causa eficiente de este vínculo solo podía ser el consentimiento mutuo. Agregaba que, en esencia, el matrimonio era la unión de las almas de los cónyuges, causa eficiente y causa formal ${ }^{16}$. Comentado la doctrina de Sánchez, Carrodeguas sintetizaba la importancia del consentimiento matrimonial en los siguientes términos: "En conclusión: el consentimiento es causa eficiente y formal extrínseca del matrimonio" ${ }^{17}$.

El consentimiento posee una faceta interna y otra externa. En cuanto al a primera, para que pueda hablarse de un verdadero consentimiento, "requiérese verdadera intención de contraer la obligación y vínculo que de ella nace”. El consentimiento externo está referido a la manifestación de dicha voluntad interna o real. En palabras de Santo Tomás de Aquino, se requiere para la constitución válida del matrimonio que las palabras externas empleadas por los contrayentes para intercambiar su consentimiento matrimonial, sean coincidentes con el consentimiento interno de quien las emite, puesto que de no darse dicha coincidencia, el acto sería nulo ${ }^{18}$.

Por lo tanto, un matrimonio contraído exteriormente sin la indicada intención "es en realidad nulo en el fuero interno, mas en el externo se le juzga válido, mientras no se demuestre la ficción con pruebas evidentes"19. Como podemos apreciar, uno de los aspectos que desde antiguo centró la atención de los autores fue la prueba de la simulación ${ }^{20}$, idéntico panorama existe en el derecho civil patrimonial $^{21}$.

En esta breve síntesis sobre la simulación canónica, no podemos dejar de mencionar la doctrina de Gasparri, cuyo antecedente fue D’Annibale ${ }^{22}$, en virtud de ser, como lo ha dicho Moreno, "el antecesor inmediato del código Pío-

15 D. $23,2,30$.

16 SÁnchez, Tomás, Disputationum de sancto matrimonii sacramento (Antuerpiae, 1626), L. II, disp. XXVI, N. 3 lib. 7, disp. 18.

${ }^{17}$ Carrodeguas Nieto, Celestino, La sacramentalidad del matrimonio. Doctrina de Tomás Sánchez S.J. (Madrid, Comillas, 2003), p. 132.

18 Santo Tomás de Aquino, Suppl., q. 45, a. 4, ad. 2.

19 Donoso, cit. (n. 7), pp. 364-365.

20 "La prueba de la simulación ha tenido tradicionalmente un punto de dificultad específico, que radica precisamente en que se trata de valorar la real existencia de un acto que por su naturaleza es una voluntad interna, conocida directamente sólo por el simulante y de la que se tiene sólo noticia indirecta”, GAS AIXENDRI, Monserrat, La exclusión del bonum fidei y su prueba. Doctrina y jurisprudencia, en IC. 51 (2011), 51, p. 219.

${ }^{21}$ En este sentido, se ha sostenido que: "El aspecto práctico más llamativo en esta materia es el de la dificultad de la prueba de la simulación. Fue aquel sobre el que se centrara la atención de la antigua doctrina. Exige de los letrados máximo esfuerzo imaginativo y hasta un cierto instinto policíaco; imponiendo a los jueces una tarea de la mayor delicadeza”, De CASTRO Y Bravo, Federico, El negocio jurídico (Madrid, Civitas, 2002), p. 366.

22 D'Annibale, Summa theologia moralis (Romae, 1891), pars II, lib. 3, De contractibus, $\$ 412,330-331$. 
Benedictino sino especialmente por contener los principios doctrinales sobre la simulación que fueron positivados en el Codex"23. Gasparri con gran lucidez expuso y desarrolló la importancia del acto positivo excluyente de la voluntad, realizado por el sujeto simulante, para efectos de poder afirmar la nulidad del matrimonio en consideración a la simulación realizada ${ }^{24}$. Esto es, no es suficiente con un acto meramente interpretativo, debe el acto oponerse a la voluntad general o implícita de contraer matrimonio ${ }^{25}$.

En definitiva, para el derecho canónico la simulación era -y sigue siendouna causal de nulidad del matrimonio. Los canonistas han sabido distinguir y desarrollar tanto el aspecto interno como la faceta externa del consentimiento matrimonial. La nulidad matrimonial provocada por la simulación se fundaba en la falta de congruencia entre la voluntad interna y la voluntad que declaraban los cónyuges. Así, para el derecho de la Iglesia católica, ambos mencionados elementos del consentimiento matrimonial son relevantes. El referido tratamiento de la simulación sería recepcionado en el código de Bello, según veremos a continuación.

El derecho canónico ha seguido reconociendo la relevancia de la simulación en el matrimonio, a diferencia de lo que ha sucedido en Chile. El descrito estado de cosas se vería plasmado en la codificación canónica, de esta manera, el consentimiento, en su aspecto interno y externo, continúa siendo objeto de disciplina canónica. En el Código de Derecho Canónico de 1917, el canon 1086 aceptaba la simulación, al sancionar la exclusión vía acto positivo de voluntad del matrimonio mismo o de una propiedad esencial. Por su parte, en similares términos, en el Código de Derecho Canónico de 1983, la norma fundamental en la materia que nos ocupa es el canon 1101. En su parágrafo $₫ 1$ se establece que "El consentimiento interno de la voluntad se presume que está conforme con las palabras o signos empleados al celebrar el matrimonio". Agrega el parágrafo 2, en directa referencia a la simulación, "Pero si uno o ambos contrayentes excluyen con un acto positivo de la voluntad el matrimonio mismo, o un elemento esencial del matrimonio, o una propiedad esencial, contraen inválidamente". Podemos apreciar que se agregó la referencia a la exclusión de los elementos esenciales del matrimonio. Comentando lo último, Peña expresa que se trata de una ampliación meramente formal, puesto que desde un punto de vista objetivo "los elementos esenciales del matrimonio, a diferencia de las propiedades esenciales, son elementos constitutivos del matrimonio mismo, que entran necesariamente en su definición o esencia metafísica, de tal modo que la exclusión de alguno de ellos supone la exclusión del objeto mismo del consentimiento, es decir, la exclusión del matrimonio mismo"26.

23 Moreno Ramírez, Domingo cit. (n. 8), p. 256.

${ }^{24}$ Gasparri, Pietro, Tractatus canonicus de matrimonio, N. 903.

25 Benedicto XIV, De synodo diocesana libri tredecim, lib. 13, c. 22, n. 8.

26 PeÑA García, Carmen et al, Matrimonio: nulidad canónica y civil, separación y divorcio. Aspectos sustantivo y procesal conforme a la nueva Ley de Enjuiciamiento Civil, en 0'CALLAGHAN, Xavier (coord.), (Madrid, Editorial Centro de Estudios Ramón Areces, S.A., 2001), p. 82, cita 304. 
2. El Código Civil de Bello: se mantiene la vigencia del derecho canónico a propósito del matrimonio

Como hemos indicado, el panorama descrito no sufrió alteración alguna con la dictación del Código Civil, el que entró en vigencia el 1 de enero de 1857 . El derecho de la Iglesia católica siguió rigiendo el matrimonio ${ }^{27}$, en consecuencia, el derecho canónico se aplicaba a los requisitos de validez del matrimonio, a los impedimentos y prohibiciones, a la celebración, solemnidades y disolución del mismo. El mismo Bello justificaba su opción en una nota al artículo 118 del Proyecto de 1853, norma coincidente con el tenor del inciso $2^{\circ}$ del artículo 103 del Código Civil: "¿a qué poner como leyes las que no dirigirian a la autoridad eclesiástica, única competente en materia de matrimonios? Esta autoridad se regiría siempre por las disposiciones del derecho canónico; y el texto del Código Civil sería para ella una letra muerta [...] En este orden de cosas, la ley civil no puede menos de estar al juicio de la autoridad eclesiástica sobre la validez del matrimonio" 28 . Con todo, Bello era consciente que un porcentaje de la población, aunque fuese claramente minoritario, no adhería a la religión católica, aspecto que fue considerado en el texto del Código Civil a propósito de la regulación del matrimonio.

Así, el texto original del mencionado código regulaba el matrimonio tanto para los que profesaban la religión católica como para los no católicos. A mayor detalle, en conformidad a lo dispuesto en el inciso $2^{\circ}$ del artículo 103 , norma que reguló el matrimonio entre los católicos, "La ley civil reconoce como impedimentos para el matrimonio los que han sido declarados tales por la Iglesia católica; y toca a la autoridad eclesiástica decidir sobre su existencia y conceder dispensas de ellos".

Por su parte, el artículo 118 trataba la situación del matrimonio entre no católicos en los siguientes términos: "Los que profesando una religión diferente de la católica quisieren contraer matrimonio en territorio chileno, podrán hacerlo, con tal que se sujeten a lo previsto en las leyes civiles y canónicas sobre impedimentos dirimentes, permiso de ascendientes o curadores, y demás requisitos; y que declaren ante el competente sacerdote católico y dos testigos, que su ánimo es contraer matrimonio, o que se reconocen el uno al otro como marido y mujer; y haciéndolo así, no estarán obligados a ninguna otra solemnidad o rito".

Bello optó, razonablemente en nuestra opinión, en continuar entregando la disciplina del matrimonio al derecho de la Iglesia católica. Concordamos con dicha opción puesto que la población de Chile, en su gran mayoría, profesaba la fe católica. Como hemos señalado en otra oportunidad, "el derecho debe ser fiel expresión del medio social al que es aplicable y por tanto, debe responder a las necesidades de éste, y el Chile de 1857, era un país mayoritariamente católico, de forma tal que el único matrimonio al que la inmensa mayoría de nuestra sociedad le reconocía valor, era el matrimonio religioso, no asignándosele valor alguno al matrimonio civil" ${ }^{29}$. Además, desde un punto de vista estrictamente jurídico,

27 Salinas Araneda, Carlos, cit. (n. 1), pp. 81-82.

${ }^{28}$ Véase, Salinas Araneda, Carlos, El error en el matrimonio (Santiago de Chile, Universidad Central de Chile, 2005), II, p. 450.

${ }^{29}$ Mondaca Miranda, Alexis, El error en las cualidades en el derecho matrimonial chileno (Santiago de Chile, Thomson Reuters La Ley, 2015), p. 32. 
no existen dudas respecto de que el derecho canónico era el ordenamiento más técnico y avanzado para regular el matrimonio, poseía dicho derecho una vastísima experiencia en la materia. Tengamos en cuenta, también, que a la época en América Latina el único matrimonio al que se reconocía validez era el religioso y que la religión católica seguía siendo la única religión oficial de Chile.

Podría llamar la atención que Bello no estableciese una disciplina del matrimonio diversa de la canónica, a diferencia de lo que ocurría con uno de sus principales modelos, el Code Napoleón de 1804. Pero la experiencia comprobó lo acertado de su decisión. En este sentido, el país se había acostumbrado a la celebración de matrimonios ante la Iglesia católica. Una vez que comenzó la aplicación de la LMC, pudo advertirse la resistencia de la población a realizar su matrimonio bajo el nuevo ropaje civil: los matrimonios canónicos continuaron celebrándose, mientras que, en una primera etapa, la cantidad de matrimonios civiles no fue elevada. Durante el primer año de aplicación de la LMC el número de matrimonios civiles no alcanzó a un tercio de la cifra de matrimonios religiosos celebrados el año inmediatamente anterior ${ }^{30}$.

Esta situación generó graves problemas. Como lo manifestó Alessandri, se produjo una desorganización de la familia manifestada en un alza de las uniones de hecho ${ }^{31}$ y aumentó el número de hijos simplemente ilegítimos ${ }^{32}$. Desde luego, ninguno de estos fenómenos fue deseado por los contrayentes; era la propia legislación vigente la que contribuía a su generación. Tales fueron algunas de las primeras consecuencias de apartarse del criterio original de Bello ${ }^{33}$.

${ }^{30}$ Se produjo una fuerte reacción de la prensa inspirada en valores católicos. Se consideraba que la LMC se oponía a la idiosincrasia nacional y que provocaría graves daños a la sociedad, como la impiedad, la disolución de la familia, el perjuicio para los fieles católicos al verse oprimidos en su conciencia y el descrédito de los mismos dentro y fuera del país, EsCUDERO MirANDA, María Consuelo, La Iglesia católica en Chile frente a la ley de matrimonio civil 1870-1895 (Memoria de Grado, Pontificia Universidad Católica de Valparaíso, Valparaíso, 1992), p. 155.

${ }^{31}$ Dado que los contrayentes se casaban ante la Iglesia católica, pero no ante el oficial del Registro Civil competente, el derecho civil no reconoció valor alguno a tales matrimonios; luego, solo podían ser entendidos como meras relaciones de concubinato. Lo anterior fue establecido por la jurisprudencia al resolver los conflictos relativos a los bienes adquiridos por los c o n c u b i n o s : puesto que no se les reconocía que habían celebrado un matrimonio, no podía hablarse obviamente de sociedad conyugal, en consecuencia, para resolver los temas patrimoniales que la adquisición de bienes generaba, se concluyó que se trataba de uniones de hecho y que respecto de los bienes se había constituido el cuasicontrato de comunidad. Así lo establecía el art. 1 de la LMC: "El matrimonio que no se celebre con arreglo a las disposiciones de esta ley, no produce efectos civiles. Es libre para los contrayentes sujetarse o no a los requisitos y formalidades que prescribe la religión a que pertenecieren. Pero no se tomarán en cuenta esos requisitos y formalidades para decidir sobre la validez del matrimonio ni para reglar sus efectos civiles", Alessandri Rodríguez, Arturo, Precedencia del matrimonio civil al relijioso (Santiago de Chile, Imprenta Universitaria, 1916), p. 14.

${ }^{32}$ Con respecto a la ilegitimidad de la descendencia, nuevamente la raíz del problema se encontraba en la falta de reconocimiento del matrimonio canónico. Por lo tanto, los hijos se concebían y nacían en concubinatos, "fuera de un matrimonio legalmente celebrado", por tal motivo, no podían ser considerados como legítimos o legitimados, sino que su status filiativo era el de ilegítimo. Ibíd.

${ }^{33}$ Recordemos que en el sistema filiativo original los hijos se clasificaban en legítimos e 
Teniendo presente lo señalado, es decir, la primigenia redacción del código de Bello $^{34}$, lo dicho a propósito de la simulación en materia canónica resulta plenamente aplicable al período en comento. Por consiguiente, en virtud del Código Civil original, aquellos matrimonios en los que hubiese operado una simulación deberían haber sido calificados de nulos, en razón de la ausencia de consentimiento de la que adolecían. Este panorama se mantuvo hasta la LMC.

\section{UN CAMBIO DE DIRECCIÓN: LA LEY DE MATRIMONIO}

CIVIL DE 1884

Un hito fundamental para el presente trabajo está constituido por la LMC de 1884, normativa que empezó a regir el 10 de enero del indicado año. En efecto, con la entrada en vigencia de la primera disciplina nacional laica del matrimonio, éste deja de ser regulado por el derecho canónico. Incluso, cesa la producción de efectos civiles del matrimonio canónico y el matrimonio civil fue el único matrimonio reconocido por el derecho ${ }^{35}$.

Según Carrión, analizando la falta de disciplina expresa de la simulación de matrimonio en el derecho civil de España, aunque consideramos que sus razonamientos son aplicables al derecho de familia de Chile, "la tesis de la irrelevancia se apoyará sobre dos pilares fundamentales respecto a los cuales el resto de los argumentos constituirán mero complemento: el principio de certeza y estabilidad del estado civil de las personas y la rigurosa identificación del consentimiento matrimonial con el manifestado en sede de celebración. Todo lo anterior completado con la imposibilidad de dar acogida a los criterios canónicos"36.

Ha explicado Salinas que "Sabido es que los Estados, al legislar sobre el matrimonio civil, en el fondo no hicieron sino una lectura en clave laica del matrimonio canónico; la estructura jurídico-canónica del matrimonio se mantuvo casi intacta, sólo que cambió de color: si en el derecho canónico el matrimonio se celebraba ante un párroco, ahora lo fue ante un funcionario estatal; si el párroco leía unos versículos del Evangelio, ahora se hacía escuchar a los contrayentes unos artículos del Código Civil”37.

ilegítimos. A su vez, la filiación ilegítima podría ser natural o simplemente ilegítima. En el primer caso se determinaba la filiación por reconocimiento o por sentencia judicial, mientras que en el segundo, la filiación no se encontraba determinada.

${ }^{34}$ En sede de derecho civil patrimonial, se analiza la simulación sobre la base del tenor del art. 1707 del Código Civil en cuya virtud, "Las escrituras privadas hechas por los contratantes para alterar lo pactado en escritura pública, no producirán efecto contra terceros. Tampoco lo producirán las contraescrituras públicas, cuando no se ha tomado razón de su contenido al margen de la escritura matriz cuyas disposiciones se alteran en la contraescritura, y del traslado en cuya virtud ha obrado el tercero".

35 La NLMC ha reconocido los efectos civiles del matrimonio religioso, en la medida que se cumplan los requisitos establecidos en su art. 20.

36 CARRIón, Salvador, En torno a la simulación del matrimonio civil, en RDP., 65/1, (1981), pp. 43-45.

37 Salinas Araneda, Carlos, Derecho canónico, matrimonio y nulidad, en RDUCV., 15 (1993-1994), p. 603. 
En el mismo sentido del párrafo anterior, en palabras de Ferrer "El calco de la disciplina canónica era casi completo pero tenía algunas excepciones. Así, y por lo que a nosotros respecta, es digno de ser subrayado el art. 92 que reproducía fielmente las causas canónicas de nulidad a excepción de la simulación de tal manera que el elenco en materia de consentimiento quedaba limitado a los supuestos de error en la persona, coacción y miedo grave. En consecuencia, puede afirmarse que la ley de 1870 supuso la civilización de la regulación canónica del matrimonio en general, pero no de la simulación canónica" ${ }^{38}$.

La LMC de 1884 no reguló en términos explícitos los requisitos de existencia del matrimonio. Por lo tanto, no se disciplinó la sanción aplicable para los supuestos de ausencia del debido consentimiento matrimonial como acontece con la simulación. Lo anterior es sin perjuicio del tratamiento otorgado a la demencia como impedimento dirimente absoluto ${ }^{39}$ y de la inhabilidad de los actualmente privados de razón para ser testigos del matrimonio ${ }^{40}$. Panorama diverso sucedió con los requisitos de validez, los que sí fueron objeto de regulación expresa, tal fue el caso de la falta de un libre y espontáneo consentimiento y de la capacidad o de la ausencia de impedimentos.

Teniendo presente lo recientemente señalado, las principales normas que se referían al consentimiento se encontraban en el parágrafo II, bajo el epígrafe " $D e$ los impedimentos i prohibiciones" (artículos 4 a 8), en el parágrafo III (artículos 9 a 15), denominado "De las dilijencias previas a la celebración del matrimonio", en el parágrafo 4\%, "De la celebración del matrimonio" (artículos 16 a 18) y en el parágrafo VI, "De la nulidad del matrimonio" (artículos 29 a 36). En concreto, los artículos más pertinentes para el presente trabajo son los siguientes: inciso $1^{\circ}$ del artículo 9, artículos $10,11,12,15$, inciso $2^{\circ}$ del artículo 17 , y artículos 32 y 33, según veremos a continuación.

El inciso $1^{\circ}$ del artículo 9 regulaba la manifestación como una diligencia previa al matrimonio, exigiendo que al manifestar los futuros cónyuges su ánimo de contraer matrimonio proporcionasen información relativa a una serie de antecedentes personales y familiares, y en lo que nos interesa, "el hecho de no tener impedimento o prohibicion legal para contraer matrimonio", como se agregaba en la parte final del precepto ${ }^{41}$. El artículo 10 prescribía, para el caso de manifestación verbal, que debía extenderse un acta completa de la misma. El artículo 11, a propósito del

${ }^{38}$ Ferrer OrTIZ, Javier, La simulación en el derecho matrimonial español. Estudio comparado con el derecho canónico, en IC. 33 (1993), 66, p. 646.

${ }^{39} \mathrm{El}$ art. 4 contenía el catálogo de impedimentos dirimentes absolutos, y en su no 4 prescribía "Los dementes".

${ }^{40} \mathrm{La}$ falta de aptitud para ser testigo se normaba en el art. 14, precepto que en su no 3 aludía a "Los que actualmente se hallaren privados de la razon".

${ }^{41}$ Art. 9: "Los que intentaren contraer matrimonio lo manifestarán por escrito o verbalmente al oficial del Rejistro Civil del domicilio o residencia de cualquiera de ellos, espresando sus nombres $i$ apellido paterno i ninterno; el lugar de su nacimiento; su estado de solteros o viudos, i en esto caso, el nombre del cónyuge i el 1 ugar i fech a de la muertc; su profesion u oficio; los nombresi apellidos de los padres, si fueren conocidos; los de las personas cuyo consentimiento fuere necesario; $i$ el hecho de no tener impedimento o prohibicion legal para contraer matrimonio". 
asenso requerido a los menores hábiles para contraer matrimonio, exigía acompañar a la manifestación "constancia fehaciente del consentimiento para el matrimonio".

De especial relevancia para nuestro estudio es el artículo 12, en el que se establecía el modo en que debía acreditarse el cumplimiento de los requisitos del matrimonio: "En el momento de presentar o hacerse la manifestación, los interesados rendirán información de dos testigos por lo menos, sobre el hecho de no tener impedimentos ni prohibiciones para contraer matrimonio".

La preocupación del legislador por la manifestación del consentimiento se concretó en el inciso $2^{\circ}$ del artículo 17, en cuya virtud, el oficial del Registro Civil debía preguntar a los futuros contrayentes si consentían en recibirse el uno al otro como marido y mujer, " $i$ con la respuesta afirmativa, los declarará casados en nombre de la lei".

El artículo 15 regulaba los matrimonios realizados en el extranjero según las leyes del mismo país, de acuerdo a este precepto dicho matrimonio "producirá en Chile los mismos efectos que si se hubiere celebrado en territorio chileno". Lo anterior, siempre que se hubiesen respetado los impedimentos dirimentes (absolutos y relativos), puesto que en caso contrario, "la contravención producirá en Chile los mismos efectos que si se hubiere cometido en Chile".

Finalmente, se reguló el consentimiento exento de vicios. Así, en sede de nulidad, en conformidad al artículo 32 "Es tambien nulo el matrimonio para cuya celebracion no ha habido, por parte de alguno de los contrayentes, libre i espontáneo consentimiento". Los vicios de los que podía adolecer el consentimiento matrimonial se indicaban en el artículo 33, en cuya virtud faltaba el libre y espontáneo consentimiento si existía error en cuanto a la identidad de la persona del otro contrayente $^{42}$, fuerza en los términos de los artículos 1456 y 1457 del Código $\mathrm{Civil}^{43}$ y rapto de la mujer, siempre que ésta no hubiese recuperado su libertad al momento de la celebración del matrimonio ${ }^{44}$.

Considerando la normativa mencionada en los párrafos precedentes, podemos arribar a dos conclusiones. En primer lugar, no existía una norma que regulase en términos explícitos la simulación en el matrimonio. En segundo término, la disciplina del consentimiento se preocupó de la manifestación de éste y no de su auténtica presencia.

${ }^{42}$ La doctrina entendía incluido en la disciplina legal el error en la identidad física de la persona, discutiéndose el valor dirimente del error en la identidad social y del error en las cualidades. Pero la interpretación que restringía el yerro relevante al error in corpore se impuso en la jurisprudencia. La mayoría de la doctrina excluyó el dolo como vicio del consentimiento matrimonial, Salinas ARANEDA, Carlos, El error, cit. (n. 28), pp. 464-491.

${ }^{43}$ Es decir, la fuerza debía ser grave, injusta y determinante. A idéntica conclusión puede arribarse del análisis del vigente $\mathrm{n}^{\circ} 2$ del art. 8 de la NLMC.

${ }^{44}$ Se discutió si, además del rapto de violencia, viciaba el consentimiento el rapto de seducción, entendiendo la posición mayoritaria que ambos raptos atentaban en contra del libre y espontáneo consentimiento. La consideración de la presencia de violencia en el apoderamiento de la mujer motivó la supresión del rapto en la NLMC, puesto que se le entendió comprendido en el vicio de fuerza, MondaCa MIRANDA, Alexis, Evolución legislativa de los vicios de la voluntad a propósito del matrimonio. ¿Se ha logrado una plena protección del consentimiento matrimonial?, en $R D F ., 3$ (2014), pp. 99-137. 
En efecto, al desviarse el legislador de 1884 del modelo canónico, quedaron sin tratamiento expreso los casos de falta de consentimiento matrimonial -salvo lo relativo al impedimento dirimente absoluto de demencia-, entre los que puede incluirse a la simulación. Con todo, si la voluntad declarada de los contrayentes no coincidía con la voluntad interna o real, no podía sostenerse la presencia de un verdadero consentimiento matrimonial. Este panorama produjo que se discutiese la sanción aplicable en los supuestos de falta de voluntad de los futuros cónyuges, algunos afirmaban que procedía la nulidad, mientras que otros la inexistencia. Idéntica polémica se ha presentado a propósito de la NLMC. No profundizaremos sobre esta disputa dado que excede los márgenes del presente trabajo ${ }^{45}$.

En segundo lugar, es evidente que del análisis de las normas citadas de la LMC se desprende que el legislador civil se interesó por la manifestación formal del consentimiento de los contrayentes, no sucediendo lo mismo respecto del aspecto de fondo del mismo. En consecuencia, no existía mecanismo alguno de indagación o que se preocupase, aunque sea de una manera mínima, por la real presencia de un consentimiento respetuoso de la naturaleza del matrimonio y de sus fines. Hemos dicho que el legislador civil, llegado el momento de regular el matrimonio, tomó como modelo el derecho canónico. Con todo, llama la atención que lo anterior no sucediese a propósito de un histórico requisito de existencia del matrimonio, como lo es el consentimiento, dado que la voz s i m u la c i ó n no fue empleada por la LMC. Así, en esta parte, el derecho canónico sirvió de m o d e lo pa r c i a l para el legislador civil, puesto que éste se centró en la mera manifestación del consentimiento, no brindado la misma atención al aspecto sustancial del mismo.

\section{AusenCia DE un tRatamiento EXPLÍCiTO DE LA SIMULACIÓN EN LA NUEVA LEY DE MATRIMONIO CIVIL}

Llegados a este punto, distinguiremos entre el estado de la cuestión en el proyecto de ley de lo que en definitiva sería la ley No 19947 del texto definitivo de dicho cuerpo legal. Lo anterior, dado que en el proyecto se otorgaba un tratamiento explícito a la simulación, mientras que en la NLMC no se efectúa referencia alguna a dicha institución.

En consecuencia, se justifica el estudio del proyecto y de sus antecedentes dado que ello nos permite encontrar las razones que fundamentaron, en concepto

45 Barrientos Grandón, Javier, De la inexistencia del matrimonio en el derecho chileno, en RCD., 19/2 (2006), pp. 53-83. Con todo, Corral ha señalado que: "La simulación, aunque no recogida como causal de nulidad, puede ser vista como una forma de inexistencia del matrimonio simulado por falta de consentimiento". Corral aplica el principio "no hay nulidad sin texto expreso", Corral TAlCIANi, Hernán, El régimen de los requisitos del matrimonio y de la nulidad en la nueva ley de matrimonio civil, en Corral Talciani, Hernán y Assimakópulos Figueroa, Anastasía (eds.), Cuadernos de extensión jurídica No 11: Matrimonio civil y divorcio. Análisis crítico y criterios para la aplicación de la ley $N^{o}$ 19.947, de 2004 (Santiago de Chile, Universidad de Los Andes, 2005), p. 42. En el mismo sentido, Barrientos Grandón, Javier y Novales Alquézar, Aránzazu, Nuevo derecho matrimonial chileno (Santiago de Chile, LexisNexis, 2004), p. 220. 
del legislador, la supresión de la simulación y, por lo tanto, la perpetuación de la falta de disciplina jurídica de la misma en sede de derecho matrimonial civil.

\section{Proyecto de nueva ley de matrimonio civil}

Como hemos afirmado, a diferencia de lo que sucedió tanto en la LMC de 1884 como en la NLMC, el proyecto de lo que en definitiva sería la NLMC ${ }^{46}$ sí regulaba en términos expresos la simulación en el matrimonio en su artículo 9. En este sentido, establecía el inciso $1^{\circ}$ del señalado precepto, reconociendo la relevancia de primer orden que posee el consentimiento en el matrimonio: "No hay matrimonio si no existe consentimiento por parte de ambos contrayentes sobre los elementos esenciales del contrato matrimonial'. En el inciso $2^{\circ}$ se consagraba como sanción la nulidad respecto de los matrimonios simulados en los siguientes términos: "Si se simula un matrimonio que no corresponde a la real intención de los contrayentes, se contrae inválidamente". Resulta evidente que este inciso se aplicaba en forma directa a los supuestos de matrimonios d e co n ve n i e n c i a y a los matrimonios que buscan exclusivamente beneficios previsionales. Por su parte, en el inciso final del artículo 9, se establecía que procedía la nulidad si uno o ambos cónyuges excluían, en virtud de un acto de voluntad, positivo, directo y verificable en el fuero externo, alguno de los elementos esenciales del matrimonio.

Del estudio del debate que generó el artículo 9 en el Congreso Nacional se desprende que la situación de los matrimonios celebrados por los inmigrantes, eventualmente con el objetivo de burlar las normas de extranjería, preocupaba a los parlamentarios. En esta línea, afirmó el senador Viera-Gallo: “¿Cuándo se considera que sería fingido dicho vínculo? Cabe señalar que esta disposición ha sido pensada en forma especial para los inmigrantes que se casan y se quedan en determinado lugar a fin de conseguir visa de residencia permanente, o para salir del territorio cuando no lo pueden abandonar legalmente. Sin embargo, en un país como Chile, ¿de qué manera se prueba que un matrimonio fue simulado, o sea, que no correspondía a la intención de los contrayentes? ¿Qué pasa si se presentan los dos cónyuges y manifiestan que nunca pensaron en casarse, que ello fue una faramalla por la familia y que, por tanto, su matrimonio es nulo, para lo cual presentan dos o tres testigos? ¡Repito: Eso sí que se presta para fraude!”47

Con todo, la norma fue suprimida, empleándose como fundamento para ello las siguientes razones: la falta de consentimiento implica la inexistencia del matrimonio; si hay simulación tampoco existe matrimonio; podrían generarse fraudes de admitirse una regulación expresa de la simulación; ésta es completamente extraña al sistema matrimonial de Chile; y la dificultad probatoria propia de la simulación.

A propósito del primer fundamento, se hizo presente que si no había consentimiento, no existía matrimonio, por lo tanto, no se necesitaba de una norma que regulase dicha situación. Lo señalado fue afirmado, entre otros, por los senadores Viera-Gallo y Espina. Según el primero: "No hay matrimonio si no existe

46 Cámara de Diputados, Moción de los diputados Saa, Allende, Aylwin, Walker, Barrueto, Cantero, Longton, Munizaga, Elgueta y Viera-Gallo, Boletín No 1759-18, sesión 27ª especial, de 28 de noviembre de 1995, anexo de documentos, Valparaíso, p. 21.

${ }^{47}$ Diario de sesiones del Senado, sesión 24, 7 de enero de 2004, Valparaíso, pp. 529-530. 
consentimiento por parte de ambos contrayentes sobre los elementos esenciales del contrato matrimonial. ¡Eso es obvio! Porque si no hay consentimiento en tal sentido, no es necesario decirlo. Por lo tanto, la norma estaría de más" ${ }^{48}$. Indicó el segundo, "Evidentemente, el inciso primero establece algo esencial: si no hay consentimiento, no hay matrimonio. No es necesario decirlo, pues ya figura en el Código Civil en forma clara. De manera que repetir una norma ya vigente -además, con una redacción poco feliz-, nada aporta a la declaración del punto en controversia" 49 .

El segundo fundamento esgrimido para justificar el rechazo a un tratamiento expreso de la simulación matrimonial, fue que dicha regulación se estimaba innecesaria, puesto que si había simulación, no existía matrimonio. Nuevamente, Viera-Gallo intervino en la discusión parlamentaria, indicando que: "en cuanto a la segunda causal, el inciso segundo señala que [...] ¡Obvio! De nuevo lo mismo"50.

El tercer motivo del rechazo fue la posibilidad de que el artículo 9 pudiese ser utilizado en la elaboración de fraudes. Con respecto al inciso final de la norma, una vez más el senador Viera-Gallo manifestó su opinión: "podría ocurrir, por ejemplo, que ellos al momento de casarse dejen -como resguardo, por si les va mal-, una escritura ante notario manifestando su intención de no procrear y que después presenten ese documento para decir que el matrimonio está nulo porque nunca desearon procrear. Señor Presidente, me parece que es posible aprovecharse de esta norma $[\ldots]$ en un sentido plenamente fraudulento" 51 .

El temor a la producción de fraudes es comprensible en el derecho de familia de Chile. Recordemos que durante la vigencia de la LMC de 1884, en conformidad al artículo 35 de la ley 4.808 sobre Registro Civil, era competente el oficial de Registro Civil de la comuna o sección en que cualquiera de los contrayentes tuviera su domicilio o hubiese vivido durante los tres meses anteriores a la fecha de celebración del matrimonio. Considerando que el divorcio no disolvía el vínculo y que las restantes causales de nulidad matrimonial tenían poca aplicación, la supuesta incompetencia del oficial de Registro Civil fue utilizada para lograr la declaración de nulidad. Con el propósito de acreditar la incompetencia alegada se acudía a la presentación de testigos falsos ${ }^{52}$.

${ }^{48}$ Ibíd., p. 529.

${ }^{49}$ Ibíd., p. 530.

${ }^{50}$ Ibíd., p. 529.

${ }^{51}$ Ibíd., pp. 529-530. Se rechazaba la idea de que un consentimiento matrimonial ya manifestado emitido de manera consciente, libre y voluntaria, pudiese verse afectado por la declaración o incluso, por la prueba de la divergencia entre la voluntad interna y la que se declaró, Comisión de Constitución, Legislación, Justicia y Reglamento del Senado, segundo informe, boletín 1759-18, pp. 16-53.

${ }^{52}$ Según Velasco, "Este estado de cosas es de especial gravedad y constituye la expresión de un hondo problema jurídico social [...] No se trata de problemas relacionados con la competencia del Oficial autorizante, sino de la brecha que se ha abierto para solucionar problemas humanos que la ley chilena $[\ldots]$ prefiere ignorar con la indisolubilidad absoluta del matrimonio por causa sobreviniente. En consecuencia, carece de interés la cuestión puramente jurídica acerca de la nulidad por la referida infracción", VeLASCO LETELIER, Eugenio, De la disolución del matrimonio (Santiago de Chile, Editorial Jurídica de Chile, 1973), p. 173. 
Lo señalado motivó que en la NLMC se estableciese que cualquier oficial de Registro Civil era competente para celebrar matrimonios, con independencia del domicilio o residencia de los contrayentes, siempre que el mismo funcionario hubiese intervenido en las diligencias previas de $\mathrm{m}$ a $\mathrm{n}$ ifestación e información.

Como cuarto fundamento, se indicó que la simulación era una institución completamente ajena al derecho civil de Chile. En otras palabras, la admisibilidad de la simulación hubiese podido ser interpretada como una concesión indebida a la religión católica ${ }^{53}$, lo que atentaría en contra del principio de la igualdad de las confesiones religiosas consagrado en la ley de cultos. Esto último, en atención a la disciplina que el Código de Derecho Canónico de 1983 efectúa respecto de la simulación ${ }^{54}$.

Como quinto y último motivo de rechazo, se tuvo presente la dificultad en acreditar el momento en que se ha producido la simulación, para lo cual existían dos opciones: a la época de contraerse el matrimonio o a la de su declaración de nulidad por simulación ${ }^{55}$.

Lamentamos la supresión del artículo 9, no nos satisfacen los fundamentos esgrimidos para su eliminación. Con respecto a los primeros argumentos, el primero apunta a lo innecesario de una norma que establezca que no hay matrimonio en el supuesto general de falta de consentimiento, y el segundo, a lo superfluo de una regulación en el caso específico de simulación. Un precepto relativo a tales materias hubiese representado un quiebre con la tradición establecida en la LMC de indiferencia hacia un tratamiento explícito de los requisitos de existencia del matrimonio, resaltando la importancia del aspecto de fondo del acuerdo de voluntades de los contrayentes y subrayando la especificidad de éste, cuestiones que, para nosotros, no pueden calificarse de obvias o de in ne ces a rias. Considérese, también, que la realidad ha venido a demostrar lo útil que hubiese sido el artículo suprimido, dado que como mencionamos, la doctrina se divide a propósito de la sanción aplicable para los casos de simulación -inexistencia o nulidad-. Es decir, el artículo 9 hubiese contribuido a una mayor certeza jurídica.

Objetaremos en forma conjunta el tercer y quinto argumento. Por una parte se dijo que disciplinar la simulación conduciría a la producción de fraudes, pero por otro lado se adujo que la prueba de la simulación era particularmente difícil. Vemos una contradicción en estos dos fundamentos. En efecto, si se temía seriamente que de regularse la simulación se produciría un aumento en los fraudes matrimoniales, configurándose un escenario similar al que provocó el abuso de

53 Agrega Del Picó que sería necesario realizar un examen profundo de las sinceras y reales motivaciones de los contrayentes, lo que sólo es posible en el contexto de la aceptación de las partes del "fundamento religioso de la exploración de intenciones", lo que es posible en el caso en que se asume la pertenencia a una misma comunidad de fe, Del Picó Rubio, Jorge, Derecho matrimonial chileno (Santiago de Chile, AbeledoPerrot, 2010), pp. 227- 229.

${ }^{54}$ Código de Derecho Canónico (1983), canon 1101: "1. El consentimiento interno de la voluntad se presume que está conforme con las palabras o signos empleados al celebrar el matrimonio. 2. Pero si uno o ambos contrayentes excluyen con un acto positivo de la voluntad el matrimonio mismo, o un elemento esencial del matrimonio, o una propiedad esencial, contraen inválidamente".

55 Del Picó Rubio, cit. (n. 53), pp. 227-229. 
la causal de nulidad consistente en la incompetencia del oficial de Registro Civil, de ello se sigue que no existirían grandes obstáculos para la materialización de tan lamentable panorama. En otras palabras, se trataría de una posibilidad cierta, no de algo hipotético o eventual. Pero a reglón seguido se manifestó que era compleja la prueba de la simulación, esto es, no sería labor sencilla acreditar los mencionados fraudes, es decir, difícil sería atacar un matrimonio invocando la simulación, por consiguiente, no se conseguiría con facilidad el fin perseguido por los que han maquinado el engaño. En suma, una coherencia en la argumentación implicaría lo siguiente: se originaría un aumento en los fraudes matrimoniales dada la facilidad en fraguar y en acreditar la simulación.

Sin perjuicio de lo anterior, observaremos por separado el tercer y quinto fundamento. Con respecto al tercero, éste implica que la regulación de la simulación sería la causa de fraudes matrimoniales. Pero la realidad ha demostrado lo falso de dicha afirmación. En efecto, en Chile se verifican casos de simulación de matrimonio, no obstante que dicha figura no se encuentra regulada. Esto es, con independencia de la disciplina de la simulación matrimonial o de su ausencia, ella se produce con frecuencia, volvamos a pensar en los matrimonios d e co n v e$\mathrm{n}$ i e n c i a, fenómeno que afecta a varios países, y en cuya incidencia no influye un tratamiento jurídico explícito de la simulación o la situación contraria. Lo mismo podemos decir de los matrimonios con militares que buscan exclusivamente beneficios previsionales. Entonces, podemos preguntarnos, ¿cuál es la causa del evidente aumento de las simulaciones de matrimonio? El motivo que induce a tales fraudes se encuentra en el deseo de lograr ciertos fines, como la nacionalidad, la residencia, un contrato de trabajo, beneficios previsionales, impedir o revocar la dictación, según corresponda, de una resolución administrativa de expulsión y no, como hemos afirmado, en el estado legislativo de una determinada figura.

En cuanto al quinto argumento, es efectivo que difícil resulta la prueba de la divergencia entre la voluntad real y la voluntad que se declara, pero lo anterior no posee la entidad suficiente para que una materia sea excluida del tratamiento legislativo. Así, misma dificultad existe usualmente a propósito del dolo, de la mala fe y de los animus en general, pero de ello no se deriva que debiese omitirse su disciplina por parte del legislador.

El cuarto fundamento tampoco es admisible. El derecho canónico ha sido un histórico modelo en el ámbito matrimonial por su especial desarrollo y riqueza técnica. Recordemos que el legislador civil prácticamente se ha olvidado del aspecto interno del consentimiento, y por lo tanto, de la simulación. No apreciamos atentado alguno en contra de la igualdad de cultos por el hecho de basarse una norma en el derecho canónico. En este sentido, entendemos que la disciplina canónica de una institución no puede ser fundamento suficiente para decidir la regulación o no de una materia, lo decisivo debería ser tutelar de la mejor manera posible el consentimiento matrimonial, y la historia demuestra que en este punto el derecho de la Iglesia católica puede ser de gran utilidad, no siendo prudente desconocer sus aportes. Con todo, este fundamento no debiese llamar la atención, dado que durante la tramitación del proyecto de la NLMC, cada vez que se discutía la posibilidad de incorporar causales de nulidad basadas 
o existentes en el derecho canónico, por ejemplo, como sucedió con el error en las cualidades, se escuchaba la misma objeción ${ }^{56}$.

En definitiva, del análisis de las discusiones parlamentarias de lo que sería la NLMC, podemos arribar a las conclusiones siguientes. En primer lugar, resulta de toda evidencia que cuando el legislador se refería a la simulación en el matrimonio, entendía que en dicha hipótesis se incluían los matrimonios d e c o n v e n i e n c i a . En segundo término, además es claro que ante la ausencia de consentimiento en virtud de simulación el matrimonio no existiría, en consecuencia, no resultaría necesaria una norma que en términos expresos regulase dicha situación. Lo último a diferencia del criterio establecido en otros ordenamientos jurídicos, como en el artículo 146 del Code ${ }^{57}$, en el No 1 del artículo 73 del Código Civil español ${ }^{58}$, más específicamente en el artículo 123 del Codice Civile de $1942^{59}$ y en el artículo 406 del nuevo Código Civil y Comercial de Argentina ${ }^{60}$.

\section{Ausencia de una disciplina de la simulación en la NLMC}

Según acabamos de indicar, en el derecho matrimonial chileno, a diferencia de lo que puede apreciarse en otros ordenamientos, no se ha regulado en términos explícitos la simulación. En efecto, la NLMC ni siquiera utiliza la voz s i m u l a c i ó n , con todo, no impide su aplicación. Lo señalado es una consecuencia de una cuestión mayor: la NLMC no disciplina los requisitos de existencia del matrimonio, por lo tanto, tampoco contempla una norma general relativa a los supuestos de ausencia del debido consentimiento entre los contrayentes. Sí se otorga un tratamiento a los requisitos de validez del matrimonio y se establece como sanción de su inobservancia la nulidad, tal como se deriva del tenor de los artículos 44 y 45 de la NLMC. Esto es, se trata del mismo panorama que podía apreciarse durante la vigencia de la LMC.

Un examen de los preceptos actualmente vigentes conduce a la misma conclu-

${ }^{56}$ Según Gazmuri: "Tengo la opinión de que las causales de nulidad en la ley civil deberían ser muy determinadas, tendrían que existir impedimentos muy claros, fácilmente discernibles, lo más objetivos posibles, y no los que he mencionado [...] Otra cosa es que los católicos se sometan al derecho canónico [...] Pero esos son actos libres, que no emanan ni de la ley ni del Estado, sino de las convicciones más íntimas de las personas y de su relación voluntaria, en este caso, con la Iglesia católica”, Diario de Sesiones del Senado, sesión $24^{\mathrm{a}}$, 7 de enero de 2004, pp. 3700-3701.

${ }^{57}$ Art. 146 del Código Civil francés: "Il n'ya pas de mariage lorsqu'il n’y a point de consentement".

58 Art. 73.1 del Código Civil español: "Es nulo cualquiera que sea la forma de su celebración: 1. El matrimonio celebrado sin consentimiento matrimonial”.

59 Art. 123 del Codice Civile: "Simulazione. Il matrimonio può essere impugnato da ciascuno dei coniugi quando gli sposi abbiano convenuto di non adempiere agli obblighi e di non esercitare $i$ diritti da esso discendenti. L'azione non può essere proposta decorso un anno dalla celebrazione del matrimonio ovvero nel caso in cui i contraenti abbiano convissuto come coniugi successivamente alla celebrazione medesima".

${ }^{60}$ El citado art. prescribe: "Requisitos de existencia del matrimonio. Para la existencia del matrimonio es indispensable el consentimiento de ambos contrayentes expresado personal y conjuntamente ante la autoridad competente para celebrarlo, excepto lo previsto en este Código para el matrimonio a distancia". Agrega el inc. $2^{\circ}$, "El acto que carece de este requisito no produce efectos civiles". 
sión que indicamos a propósito de la LMC de 1884, esto es, al legislador pareciera importarle solo la manifestación formal del consentimiento, no existiendo normas que regulen los casos en que, como ocurre con la simulación, no existe consentimiento matrimonial. Para fundamentar lo afirmado, distinguiremos entre los matrimonios celebrados en Chile y los realizados en el extranjero.

A propósito de los matrimonios realizados en Chile, dos leyes resultan principalmente aplicables. Nos referimos a la NLMC y a la ley de Registro Civil No 4.808. Centrándonos en la NLMC las normas pertinentes son los arts. 9, 10, 11 y 14. Según la primera norma, los futuros contrayentes deben manifestar su voluntad de contraer matrimonio y proporcionar información relativa a sus antecedentes personales y familiares. En la parte final del inciso $1^{\circ}$ del artículo 10 se indica que los cónyuges deben declarar "el hecho de no tener incapacidad o prohibición legal para contraer matrimonio". Idéntica fórmula se encuentra en el No 7 del artículo 3 del reglamento de la NLMC. Este trámite es denominado $m$ a $n$ i fe s $\mathrm{t}$ a c i ó $\mathrm{n}$.

Según el artículo 10, es misión del Servicio de Registro Civil e Identificación otorgar determinada información a los futuros cónyuges. Así, debe informarse sobre los fines del matrimonio, los derechos y deberes que de éste emanan y los regímenes patrimoniales matrimoniales. Agrega el inciso $2^{\circ}$ que se deberá advertir a los contrayentes sobre la necesidad de que el consentimiento se encuentre ausente de vicios. El inciso $3^{\circ}$ del mismo precepto y el artículo1 1 tratan los cursos de preparación del matrimonio ${ }^{61}$.

El artículo 14 regula el segundo trámite previo a la celebración del matrimonio llamado i n for m a c i ó $\mathrm{n}$. En su virtud, mediante declaraciones de dos testigos, deben acreditar los contrayentes que no se encuentran incluidos en "impedimentos ni prohibiciones para contraer matrimonio". Esta exigencia es repetida por el artículo 7 del reglamento de la NLMC.

La ley No 4.808 disciplina la materia que analizamos en el artículo 4 y en el título II, De los matrimonios, artículo 37 a 41 . No es necesario profundizar en el estudio de estos artículos, dado que tales normas no alteran en nada la aludida regulación de la NLMC.

Los matrimonios celebrados en el extranjero se regulan en el artículo 80 de la $\mathrm{NLMC}^{62}$. De acuerdo a la primera parte del inciso $1^{\circ}$ : "Los requisitos de forma y de fondo del matrimonio serán los que establezca la ley del lugar de su celebración”. Como podemos observar, se consagra el principio lex locus regit actum. Por lo tanto, en principio, el matrimonio se rige por la ley del país de su celebración.

Según la segunda parte del inciso $1^{\circ}$ : "Así, el matrimonio celebrado en país extranjero, en conformidad con las leyes del mismo país, producirá en Chile los mismos efectos que si se hubiere celebrado en territorio chileno, siempre que se trate de la unión entre un hombre y una mujer". En otras palabras, no se aceptan en Chile los matrimonios entre personas del mismo sexo, ya sean celebrados dentro

${ }^{61}$ Estos cursos no son obligatorios. Los contrayentes pueden eximirse de ellos manifestando que conocen en forma suficiente los derechos y deberes del matrimonio. Lo último es lo que puede apreciarse en la mayoría de los casos.

${ }^{62}$ Este art. debe complementarse con el art. 81, "Los efectos de los matrimonios celebrados en Chile se regirán por la ley chilena, aunque los contrayentes sean extranjeros y no residan en Chile." 
de los límites del territorio nacional o en el extranjero. Es lógico el contenido de este precepto, puesto que la diversidad de sexo no puede burlarse con el simple recurso de contraer el matrimonio en un país que otorgue validez al matrimonio entre personas del mismo sexo ${ }^{63}$.

Agrega el inciso $3^{\circ}$, "Sin embargo, podrá ser declarado nulo de conformidad a la ley chilena, el matrimonio celebrado en pais extranjero que se haya contraido en contravención a lo dispuesto en los arts. 50, $6^{\circ}$ y $7^{\circ}$ de esta ley". Así, se aplica la nulidad si un contrayente se ve afectado por un impedimento dirimente absoluto o relativo.

Según el inciso final, "Tampoco valdrá en Chile el matrimonio que se haya contraído en el extranjero sin el consentimiento libre y espontáneo de los contrayentes". Este artículo intenta defender la presencia de un libre y espontáneo consentimiento, los vicios del consentimiento matrimonial se encuentran regulados en el artículo 8 de la NLMC ${ }^{64}$. El artículo 8, en nuestra opinión, no resulta aplicable a los supuestos de simulación. Lo anterior dado que en las simulaciones matrimoniales el problema no consiste en una voluntad viciada, sino que en algo de mayor entidad; no existe consentimiento matrimonial propiamente tal, por ello no corresponde hablar a su respecto de vicio del consentimiento alguno. Es decir, el artículo 8 no guarda vinculación con las simulaciones de matrimonio.

A mayor detalle, el matrimonio puede registrarse en el consulado del país respectivo de celebración del mismo o en el registro de la primera sección de Santiago. Para la procedencia de la primera modalidad es necesario que ambos o uno de los cónyuges sean de nacionalidad chilena, que se entregue al consulado el original del certificado de matrimonio otorgado por el país que corresponda, la presencia de ambos cónyuges identificados mediante pasaporte o cédula nacional de identidad, y que al momento de la inscripción opten por un régimen matrimonial de los existentes en Chile.

A propósito de la segunda modalidad, según el inciso $3^{\circ}$ del artículo 4 de la Ley No 4.808, es necesario que cualquiera de los contrayentes remita, debidamente legalizados, los antecedentes pertinentes al Ministerio de Relaciones Exteriores. Dicho organismo verificará su autenticidad y los enviará al Conservador del Registro Civil, quien ordenará la inscripción correspondiente.

Como podemos apreciar, nuevamente, no se ha preocupado el legislador por la faceta interna del consentimiento. En este sentido, lo que se exige en la primera modalidad es acreditar la celebración del mismo (en otras palabras, el respeto a las formalidades propias de la celebración, pero no el aspecto sustancial del acuerdo de voluntades de los futuros cónyuges), la identidad y nacionalidad de los contrayentes, y la regulación de los aspectos patrimoniales. En la segunda modalidad lo relevante es seguir un determinado procedimiento: envío de los antecedentes respectivos al Ministerio de Relaciones Exteriores y luego remisión de tales antecedentes al Registro Civil, previa comprobación de su autenticidad.

En suma, existe una armonía en el derecho matrimonial de Chile respecto a

${ }^{63}$ Ramos Pazos, René, Derecho de familia (5ª edición, Editorial Jurídica de Chile, Santiago de Chile, 2005), I, pp. 66-68.

${ }^{64}$ López Díaz, Carlos, Manual de derecho de familia y tribunales de familia (3a edición Santiago de Chile, Librotecnia, 2005), I, pp. 201-202. 
la disciplina del consentimiento en el siguiente sentido: tanto si el matrimonio se celebra en Chile como si es realizado en el extranjero, lo que interesa al legislador es el respeto por los aspectos formales comprendidos en su celebración, no ocurriendo lo mismo con los aspectos de índole sustancial. Así, la indagación sobre la presencia o ausencia de un real consentimiento no se encuentra presente en la disciplina matrimonial chilena, no existiendo norma general alguna relativa a dicho histórico requisito de existencia del matrimonio ${ }^{65}$ y menos un precepto específico que regule su simulación.

Para finalizar, no obstante la falta de un tratamiento explícito de la simulación en sede de derecho matrimonial, corresponde pronunciarnos sobre la sanción aplicable a dicha figura. Entendemos que la sanción procedente es la inexistencia, no la nulidad. En efecto, pensamos que de sostenerse que tales matrimonios son nulos, se iría en contra del principio que exige que no hay nulidad sin texto legal expreso. Para sostener lo anterior nos basamos en el tenor de los arts. 44 y 45 de la NLMC; las causales de nulidad de matrimonio se encuentran señaladas en forma taxativa por el legislador.

A mayor detalle, según la primera norma, "El matrimonio sólo podrá ser declarado nulo por alguna de las siguientes causales, que deben haber existido al tiempo de su celebración: a) Cuando uno de los contrayentes tuviere alguna de las incapacidades señaladas en el artículo 50, $6^{\circ}$ o $7^{\circ}$ de esta ley, y b) Cuando el consentimiento no hubiere sido libre y espontáneo en los términos expresados en el artículo $8^{\circ}$ ". Agrega el art. 45 que "Es nulo el matrimonio que no se celebre ante el número de testigos hábiles determinados en el artículo 17’. Es decir, tres son las causales de nulidad: incapacidad, vicios del consentimiento e inhabilidad o menor número de testigos que el exigido por la ley. Ninguna de dichas causales guarda relación con la ausencia del debido consentimiento matrimonial.

En apoyo de lo señalado, tengamos presente que en la simulación son los propios contrayentes los que han decidido excluir el contenido propio del consentimiento matrimonial, causando la ausencia de éste. Como lo ha planteado Barrientos, "Si no ha existido consentimiento matrimonial es porque no se ha ejercitado el ius conubii en su dimensión positiva y, por ende, es imposible que exista matrimonio, de modo que la inexistencia del matrimonio civil por falta de consentimiento se fundamenta en el ius conubii, al igual que el consiguiente derecho a obtener la declaración de certeza sobre el estado de soltería"66.

En este sentido se ha pronunciado, en el ámbito patrimonial León, al afirmar que puede atacarse el acto simulado y solicitarse que se declare su ineficacia por

${ }^{65}$ Lo señalado no impide que la doctrina resalte el rol de primer orden del consentimiento. Así, se ha afirmado que se comprende más integralmente el matrimonio "cuando se le asimila a la noción de pacto o acto recíproco de voluntad de los contrayentes, cuyo núcleo preceptivo radica en el consentimiento, y cuyo propósito es constituir una unión específicamente de carácter matrimonial”, Del Picó RuBio, Jorge, La ley de matrimonio civil de 2004: algunas definiciones pendientes a diez años de su entrada en vigor, en VIDAL Olivares, Álvaro et al. (coords.), Estudios de derecho civil X. Jornadas nacionales de derecho civil, Valparaiso, 2014 (Santiago de Chile, Legal Publishing Thomson Reuters, 2015), p. 152.

${ }^{66}$ Barrientos Grandón, Javier, cit. (n. 45) p. 66. 
falta de consentimiento, "puesto que en realidad sólo hay una apariencia sin contenido real. Debe preferirse la voluntad real sobre la declarada. Técnicamente el acto es inexistente" ${ }^{67}$.

Continuando en la línea de razonamiento establecida en los párrafos precedentes, consideramos que el statu quo de la simulación del matrimonio en Chile, en el sentido explicado en el presente trabajo, no impide que los jueces declaren la inexistencia de los matrimonios simulados. Así, podría deducirse una acción declarativa que tenga por objeto preciso la declaración de inexistencia, siempre que, la parte interesada soporte en forma debida el onus probandi.

Para fundamentar lo afirmado, podrían invocarse los artículos 4 y $18^{68}$ de la NLMC, relativos al consentimiento de los contrayentes. Además, el ius connubii, tratado en el artículo 2 de la NLMC, en su faceta negativa conduce a no considerar casados a los que han contraído el vínculo sin cumplir los requisitos exigidos por el ordenamiento jurídico. En otros términos, la libertad nupcial negativa consiste en el derecho a permanecer, si así se desea, en el estado de soltería, y a no ser considerado casado, a menos que se hubiese celebrado un matrimonio que respete la legislación matrimonial pertinente.

Con respecto al aspecto probatorio, la simulación puede probarse mediante pruebas indirectas. Difícil, pero no imposible, será disponer de un medio probatorio directo, por ello la doctrina señala que la divergencia entre la voluntad interna y la voluntad declarada usualmente se acredita con presunciones, como lo ha afirmado en nuestro sistema, entre otros, Díez Duarte ${ }^{69}$. En idéntico sentido se pronunció la resolución de la UE de 4 diciembre de 1997, sobre las medidas que deberán adoptarse en materia de lucha contra los matrimonios fraudulentos, la que ha establecido algunos factores cuya concurrencia puede permitir presumir que determinado matrimonio es un fraude. Tales factores son: a) no mantener una vida en común; b) falta de una adecuada contribución a las responsabilidades propias del matrimonio; c) ausencia de conocimiento entre los cónyuges con anterioridad al matrimonio; d) equivocación o desconocimiento de uno de los cónyuges sobre datos del otro (nombre, trabajo, nacionalidad, dirección, circunstancias en que se conocieron u otros datos de índole personal); e) no hablar una lengua comprensible para ambos; f) la entrega de una cantidad monetaria para

${ }^{67}$ LÉOn HurTado, Avelino, La voluntad y la capacidad en los actos jurídicos (3a edición, Santiago de Chile, Editorial Jurídica de Chile, 1990), p. 139. Con todo, hacemos presente que, en el campo del acto jurídico, se discute cuál es la sanción de los casos de falta de consentimiento. Un sector de la doctrina coincide con la ya expuesta posición de León, Claro Solar, Luis, Explicaciones de derecho civil y comparado (Santiago, Editorial Jurídica de Chile, 2015) V. V, T. $\mathrm{X}$, pp. 112-115. Otros opinan que la simulación debe ser castigada con la nulidad absoluta, en este sentido, véase AlESSANDRI BESA, Arturo, La nulidad y la rescisión en el derecho civil chileno (3 $3^{a}$ edición actualizada, Santiago, Editorial Jurídica de Chile, 2008), I, pp. 380-394.

${ }^{68}$ Este art. en su inc. 2o, a propósito de la intervención del oficial de Registro Civil en la celebración del matrimonio, prescribe que: "A continuación, leerá los artículos 131, 133 y 134 del Código Civil. Preguntará a los contrayentes si consienten en recibirse el uno al otro como marido o mujer y, con la respuesta afirmativa, los declarará casados en nombre de la ley".

69 Díez Duarte, Raúl, De la prueba del contrato. Estructura civily procesal (Santiago, Editorial Jurídica ConoSur Ltda.), 1997, pp. 268-270. 
que se celebre el matrimonio (salvo lo correspondiente por concepto de dote); g) y que el historial de uno de los cónyuges manifieste otros matrimonios fraudulentos anteriores o irregularidades en materia de residencia

En consecuencia, no es estrictamente necesaria una regulación explícita de la simulación de matrimonio, dado que, por los motivos expuestos, ésta puede ser alegada, probada y, una vez producido lo anterior, declarada por un juez.

\section{ConClusiones}

El presente trabajo nos permite arribar a las siguientes conclusiones:

1. En el tratamiento jurídico de la simulación matrimonial en Chile pueden observarse dos etapas claramente diferenciadas. En un primer estadio, en virtud de la aplicación del derecho canónico, se le consideraba una causal de nulidad del matrimonio. En el segundo estadio, la simulación no ha sido objeto de regulación expresa.

2. Según lo establecido en la conclusión precedente, con anterioridad a la entrada en vigencia del Código Civil, el matrimonio se regía por los preceptos del derecho de la Iglesia católica. En virtud de lo anterior, se distinguía la presencia en el consentimiento de un aspecto formal y de otro sustantivo. Así, se reconocía en su completa dimensión la entidad del acuerdo de voluntades de los contrayentes. Como consecuencia de lo señalado, si la voluntad que se declaraba no coincidía con la voluntad real o interna, se contraía inválidamente matrimonio.

3. La primera disciplina del Código Civil no modificó el escenario descrito en la conclusión anterior. Por consiguiente, se siguió reconociendo a la simulación como causal de nulidad matrimonial. Es decir, Bello no retiró el matrimonio del campo de aplicación del derecho canónico. Acertado fue lo anterior, dada la mayor y antigua riqueza técnica en la materia del derecho de la Iglesia católica. Además, la religión católica claramente era la profesada por la gran mayoría de la población, siendo la religión oficial del Estado. Recordemos, también, que a la época en América Latina el matrimonio religioso era el único al que se le reconocía validez.

4. El panorama señalado cambió con la LMC. En el marco del proceso de separación Iglesia-Estado, el legislador de 1884 suprimió los efectos civiles del matrimonio religioso. Esta primera regulación matrimonial laica no trató los requisitos de existencia del matrimonio, por lo tanto, la simulación tampoco fue disciplinada. Si bien es cierto se establecieron preceptos relativos al consentimiento, éstos se centraban en la manifestación formal del mismo, pero no aludieron a su aspecto sustancial, el que pasó a ser irrelevante en la letra de la ley. Es evidente que la LMC difiere en este aspecto de su modelo canónico.

5. En el proyecto de lo que en definitiva sería la NLMC, en su artículo 9, se trataba tanto la relevancia del consentimiento en el matrimonio como la simulación, la que era sancionada con la nulidad. Por los motivos enunciados en la parte pertinente del presente trabajo fue suprimido el tratamiento del consentimiento matrimonial y de la simulación. No estamos de acuerdo con lo anterior, puesto que el consentimiento de los contrayentes debe ser debidamente tutelado por el legislador, protegiéndolo de los supuestos de simulación. 
En efecto, no nos convencen los fundamentos de la supresión del artículo 9. Así, la realidad ha demostrado que no es innecesario un precepto que establezca que sin consentimiento no hay matrimonio o que regule la simulación. Consideremos también que puestos en la labor de establecer normas de tutela del consentimiento, el origen canónico o no de las mismas, debería ser irrelevante. No obsta a la señalada tarea la eventual dificultad probatoria propia de los elementos de índole subjetiva, aspecto que deberá soportar, de acuerdo a las reglas generales, el interesado en establecer la simulación, puesto que lo que se presume es la buena fe. Lo mismo respecto de un infundado temor al aumento de fraudes matrimoniales, ya que éstos reconocen diversas causas, pero no incluyéndose en éstas la disciplina explícita de la simulación.

6. La NLMC siguió el mismo sendero de su antecesora. De esta manera, silencio guardó el legislador de 2004 sobre el consentimiento como requisito de existencia del matrimonio, incluyéndose la simulación en dicho silencio, es decir, nuevamente la faceta sustantiva del consentimiento de los contrayentes fue dejada de lado. En definitiva, lo último representa el estado actual de la materia en la legislación chilena. Sin perjuicio de lo anterior, la sanción que corresponde aplicar a los supuestos de simulación es la inexistencia de matrimonio, en atención a la ausencia de consentimiento provocada por el acuerdo simulatorio. Es improcedente la nulidad debido a que lo impide el principio no hay nulidad sin texto.

Con todo, la realidad se ha impuesto, los crecientes flujos migratorios recibidos por Chile y los problemas jurídicos de ellos derivados, al igual que los matrimonios que persiguen en forma exclusiva beneficios previsionales, han puesto de manifiesto la necesidad de un tratamiento explícito del consentimiento matrimonial y de los supuestos de ausencia del mismo. De esta manera, se retomaría la senda canónica que implica el reconocimiento de la relevancia de primer orden que presenta el acuerdo de voluntades de los contrayentes, y el derecho chileno se pondría al día con determinados ordenamientos extranjeros que sí reconocen expresamente la importancia del consentimiento matrimonial, tal como sucede, entre otros países, en Francia, España, Italia y Argentina.

\section{BiBLIOGRAFÍA}

Alessandri Besa, Arturo, La nulidad y la rescisión en el derecho civil chileno (3a edición actualizada, Santiago, Editorial Jurídica de Chile, 2008), I.

Alessandri Rodríguez, Arturo, Precedencia del matrimonio civil al relijioso (Santiago de Chile, Imprenta Universitaria, 1916).

Aznar Gil, Federico, El nuevo derecho matrimonial canónico (2a edición, Salamanca, Bibliotheca Salmanticensis Estudios 60, Universidad Pontificia de Salamanca, 1985), II.

BAÑARES, Juan Ignacio, Simulación y error - ignorancia, en BAÑARes, Juan Ignacio (dir.), Simulación matrimonial en el derecho canónico (Pamplona, Eunsa, 1994), pp. 139-160.

BenEDICTO XIV, De synodo diocesana libri tredecim, lib. 13, c. 22, n. 8.

Barrientos Grandón, Javier, De la inexistencia del matrimonio en el derecho chileno, en $R C D$., 19/2 (2006), pp. 53-83. 
Barrientos Grandón, Javier y Novales Alquézar, Aránzazu, Nuevo derecho matrimonial chileno (Santiago de Chile, LexisNexis, 2004).

CARRIÓn, Salvador, En torno a la simulación del matrimonio civil, en RDP., 65/1 (1981), pp. 35-64.

Carrodeguas Nieto, Celestino, La sacramentalidad del matrimonio. Doctrina de Tomás Sánchez S.J. (Madrid, Comillas, 2003).

Claro Solar, Luis, Explicaciones de derecho civil y comparado (Santiago, Editorial Jurídica de Chile, 2015) V. V, T. X.

Corral TalCiani, Hernán, El régimen de los requisitos del matrimonio y de la nulidad en la nueva ley de matrimonio civil, en CORRAL TalCiani, Hernán y Assimakópulos FigueroA, Anastasía (eds.) Cuadernos de extensión jurídica No 11: Matrimonio civil $y$ divorcio. Análisis crítico y criterios para la aplicación de la ley No 19.947, de 2004 (Santiago de Chile, Universidad de los Andes, 2005), pp. 37-75.

D'AnNibale, Summa theologia moralis (Romae, 1891), pars II, lib. 3, De contractibus, $\$ 412,330-331$.

De Castro y Bravo, Federico, El negocio jurídico (Madrid, Civitas, 2002).

Del Picó Rubio, Jorge, Derecho matrimonial chileno (Santiago de Chile, AbeledoPerrot, 2010).

-- La ley de matrimonio civil de 2004: algunas definiciones pendientes a diez años de su entrada en vigor, en VIDAL OlIVARES, Álvaro et al. (coords.), Estudios de derecho civil X. Jornadas nacionales de derecho civil, Valparaiso, 2014 (Santiago de Chile, LegalPublishing Thomson Reuters, 2015), pp. 149-161.

Díez Duarte, Raúl, De la prueba del contrato. Estructura civil y procesal (Santiago, Editorial Jurídica ConoSur Ltda., 1997).

Donoso, Justo, Instituciones de derecho canónico (París, Librería de Rosa y Bouret, 1854), II.

Escudero Miranda, María Consuelo, La Iglesia católica en Chile frente a la ley de matrimonio civil 1870-1895 (Memoria de Grado, Pontificia Universidad Católica de Valparaíso, Valparaíso, 1992).

FERRER ORTIZ, Javier, La simulación en el derecho matrimonial español. Estudio comparado con el Derecho canónico, en IC., 33 (1993), 66, pp. 641-712.

Gas AIXendri, Monserrat, La exclusión del bonum fidei y su prueba. Doctrina y jurisprudencia, en IC., 51 (2011), pp. 207-234.

-- La formulación del concepto "acto positivo de voluntad", contrario al matrimonio hasta el CIC 1983, en Kowal, J. y Llobell, J. (eds.), "Iustitia et iudicium”. Studi di Diritto matrimoniale e processuale canonico in onore di A. Stankiewicz (Città del Vaticano, Libreria Editrice Vaticana, 2010), pp. 753-779.

GaSPARRI, Pietro, Tractatus canonicus de matrimonio, N. 903.

Hervada, Javier, La simulación total (comentario a la sentencia de la S.R.R. de 22-111961, c. Canals), en HervadA, Javier, Vetera et Nova. Cuestiones de derecho canónico $y$ afines (1958-1991), I, pp. 237-293.

LÉON HuRTAdo, Avelino, La voluntad y la capacidad en los actos jurídicos (3a edición, Santiago de Chile, Editorial Jurídica de Chile, 1990).

Lombardo, Pedro, Sententiarum libri quatuor, L. IV, dist. 27, N. 3 (Antuerpiae, 1757).

MondaCa Miranda, Alexis, Los nexos de familia y la revocación de las resoluciones de expulsión de extranjeros, en LEPÍn MOLINA, Cristián (coord.), Estudios de derecho familiar (Santiago de Chile, Thomson Reuters, 2016), I, pp. 373-388. 
-- El error en las cualidades en el derecho matrimonial chileno (Santiago de Chile, Thomson Reuters La Ley, 2015).

-- Evolución legislativa de los vicios de la voluntad a propósito del matrimonio. ¿Se ha logrado una plena protección del consentimiento matrimonial?, en RDF, 3 (2014), pp. 99-137.

-- De los matrimonios simulados, comúnmente denominados matrimonios de conveniencia o matrimonios por complacencia, de su prueba y de la lucha jurídica en su contra, en Domínguez hidalgo, Carmen et al. (coords.), Estudios de derecho civil VIII. Jornadas nacionales de derecho civil, Santa Cruz (Santiago de Chile, LegalPublishing Thomson Reuters, 2012), pp. 105-114.

-- Reflexiones sobre uno de los desafios que la inmigración plantea al derecho de familia: los asi denominados matrimonios de conveniencia, en ELORRIAGA DE BONIS, Fabián (coord.), Estudios de derecho civil IX. Jornadas nacionales de derecho civil, Viña del Mar, 2011 (Santiago de Chile, Abeledo Perrot LegalPublishing, 2011), pp. 41-54.

Moreno Ramírez, Domingo, Relevancia de la sacramentalidad del matrimonio en relación con la nulidad del consentimiento (Madrid, Ediciones Universidad San Dámaso, 2014).

Panormitanus, en X 4, 1, 26.

PeÑa GarCía, Carmen et al, Matrimonio: nulidad canónica y civil, separación y divorcio. Aspectos sustantivo y procesal conforme a la nueva Ley de Enjuiciamiento Civil, en O’Callaghan, Xavier (coord.) (Madrid, Editorial Centro de Estudios Ramón Areces, S.A., 2001).

Salinas ARANEDA, Carlos El error en el matrimonio (Santiago de Chile, Universidad Central de Chile, 2005).

-- Derecho canónico, matrimonio y nulidad, en RDUCV., 15 (1993-1994), pp. 591-607. -- El influjo del derecho canónico en el Código Civil de la República de Chile (Valparaíso, Ediciones Universitarias de Valparaíso, 2006).

SÁnCHEZ, Tomás, Disputationum de sancto matrimonii sacramento (Antuerpiae, 1626),

L. II, disp. XXVI, N. 3 lib. 7, disp. 18.

Santo TomÁs de Aquino, Suppl., q. 45, a. 4, ad. 2.

Sicardo de Cremona, Summa, in. C. 29, q. 1.

Velasco Letelier, Eugenio, De la disolución del matrimonio (Santiago de Chile, Editorial Jurídica de Chile, 1973). 